of 1847 be renewed,-it would not pass, as it has done, without our praise and special wonder.

Impressed, through love of our profession, with respect for each other, and thus, under the genial influences of a true professional brotherhood,-with an earnest, forward-springing sympathy for all our own true men beyond the walls, - with this wide, primitive, old.charter extension of our fellowship to " the faculty universal of medicine," what cheerfulness and vigour might we not afford to our distant stragglers and colonists-what advantage and protection to the public at largewhat comfort, honour, and safe conscience, each man to himself. Our praise would then indeed be distinction-our censure disgrace. The confusion of purpose, the small, vestry. like squabbles in our domestic councils, that bring pain to every true physician, and disgrace us collectively before the legislature, would merge in the paramount sense of duty to our powerful united order, and in admiration of its common mission. Strong in will, consistent in design, we could compel at any time the minister of the day,- -whether mesmerist, homoopathist, or more orthodox allopathist, to the full discharge of his duty, as guardian ex officio of the public health, not only to introduce the fitting sanitary measures, but to carry them ont and through without delay. Quick to feel, and swift to punish, we should resent, in our corporate sym. pathy, an injury, the slightest, to a part, as an outrage to the whole. There is a false "nervous theory," which I have taken some pains, in these lectures as or other occasions, to ridicule and denounce-I allude to the received popular error that assumes for the-nervous structure a capability of impression, simultaneous, instantaneous, and uniform, through all its parts and divisions. May this false theory of the nervous influence now and for ever prevail in the liead, trunk, and several members of our united professional body! May even a tread on the toe by iron boot or silken slipper-if done in violence or disrespect-be folt, by the entire section as by the individual, with instant force of sympatly, by a shock everywhere the same, and everywhere at once. Thus, and thus only, in this land of club and caste, can we of the profession be safe, in matters of our profession, from contrived and public wrong. An unjust fiscal levy on our precarious annual gains, the low tyranny, the shabby pilferings, the lofty insolence of office, whether under guardianship or in commission, the slighting and disparagement, by post or pay, of those among us who, in fleets and armies, serve their sovereign,-all these spurns, rubs, and exactions would then lie for judgment and redress in the high court of appeal of our London national council of surgery and medicine.

Firm in our union, when confident of our right, we should not quail before the Horse-guards, maintaining the truth, if need be, in the House of Commons as with the house of Somerset. No disrespect, Sir President, and fellows, I beg of you to believe, in this revolutionary juncture, to our constituted authorities. Deeply interested in the subject which I have undertaken to lay before you, (for than pain what is sadder or more terrible to bear? what in art or morals more admirable than the means and the courage which, in a good cause, defy and subdue it?) engaged as I am in the task which Harvey once discharged, forgive me if, unconsciously, I at times escape from the conventional accidents of place and station. In the assertion of a great catholic principle-in the earnestness of my plea for the dignity, comfort, and interests of all my brethren of all classes of the profession, I saw not, as I spoke, that I stood before the official dignitaries of our College-nay, had even for a brief moment forgotten the distinction between a fellow and a licentiate. Besides, Sir, in saying what I have said, I saw, felt, and knew, that in this matter of pain, I was addressing those who were in earnest like myself-who were thinking, intently thinking, while I spoke,-and thinking as I would wish them, with their hearts; that my words passed on to men who belicve, as I do, in a high physic, in a theory and practice of medicine which acknowledges a mission beyond that of routine prescription and fashionable midwifery - whose gains are incompatible with a forty-finger faculty for fees. I make no apology, I offer no excuse for this apparent digression from pain, its varieties and treatment-pain, which as a symptom, solitary, partial, and least to be communicated, is yet of physical effects the most social by inference, sympathy, and result. In the matter of pain, as of all that is most practical in his calling, here is the physician's true device-

Homo sum, humani nihil a me alienum puto.

"Any man who can afford to send a ship to sea, can afford to send a surgeon on board of her."-A Shipowner to the A uthoress of the Englishwoman in A merica, p. 108. $\underset{\text { OF }}{\text { Analpses }}$

COMMUNICATIONS IN MS. RECEIVED FOR PUBLICATION IN THE LANCET.

REMARKS ON THE EMPLOYMENT OF CHLORO. FORM AND ETHER IN THE TREATMIENT OF DISEASE, AND IN PARTURITION.

On the Infiuence of Chloroform on the Organism, and on the Production of Ancesthesia. By W. M. FaIrBmotuln, Esq., M.R.C.S.E., London.

Mr. Farrorother asks-" 1 . Does this agent act from direct contact with the sentient nervous extremities, or is it previously received into the circulation?

"Some years ago, the action of many poisons by direct con. tact with the terminal loops of the nerves of the stomach was more generally believed than at present. The almost incredible rapidity with which sulstances, after being swallowed, can be detected in the blood and urine, has led many inquirers to agree that most poisons and remedies act by their being taken into the circulation. The vapour of chloroform passing into the lungs, mingled with a portion of atmospheric air, the place and function of which, for the time, it usurps, is doubtless quickly absorbed through the air-cells and carried to all parts of the system. The theory of nervous transmission is not so plainly to be understood; for as the pulmonary branches of the pneumogastric and sympathetic, combined with the nasal branches of the oplithalmic division of the fifth nerves, and those from the olfactory lobules, are chiefly implicated, it is not very easy to conceive why their excitement should cause the remote thrill which is so immediately felt at the extremities of the fingers and toes. But when, through the medium of the circulation, we have the cerebral and excito-motory nerves stimulated to action, the carotids throb, the brachial and femoral trunks seem to leap from their attachments, the ophthalmic artery pours its column of blood into the branches distributed to the delicate structures of the eye, and spectra appear. To this short stage occurs a strangely pleasing dream, and the mind is driven afloat into oblivion.

" 2 . Is its influence so transient and harmless as is generally believed?

"Many individuals are so constituted as to be with difficulty rendered completely insensible by chloroform. Of active mind, and suspicious, they strive against those sensations which precede it; while others, on the contrary, are very quickly affected. This dissimilarity of temperament is the great bar to any certain proportion of chloroform being assigned as a proper and harmless dose. I lately inhaled one ounce, in six portions, continuously, but at no time was complete unconsciousness produced, every casual sound being painfully exaggerated. In this state the faculty of memory was remarkably increased, and slight and totally forgotten circumstances were retraced with great accuracy. This seems analogous to that state of delirium, in fever, where the mind, exhausted, calls up the thoughts of previous years, which seem, as they are uttered, to be but purposeless fancies. This feeling returns, with some, at intervals, and with decreasing power, and then entirely subsides. Whether chloroform in a large and powerful dose is entirely harmless, is a question very difficult to decide, when the minute anatomy of the nervous system is carefully considered. It has been proved that its constant and repeated use becomes speedily fatal.

"Numerous circumstances prolibit its use. Diseases of the heart and pulmonary diseases scarcely need be named, as they obviously do not admit of its application; and this is proved by the experiments of Mr. T. Wakley, (see Tre L LNCET for Jan. 1st, 1848.) But there are some which require most careful inquiry-aneurism, a previous attack of apoplexy, paralysis, angina-pectoris, and other diseases. The indiscriminate use of chloroform in dental surgery and trifling operations ought to be deprecated; or, if used, a minimum dose would have a sufficient effect with those who are easily placed under its influence; for those who are not, a momentary pain is surely better than a possible dangex."

Advantageous Employment of Chloroform under severe Shocks to the System; with Remarks on its Administration.

By W. D. Enmetr, Esq., M.R.C.S.E., Darlington.

"IN the following case of compound fracture of the leg, the inhalation of chloroform was found to be markedly beneficial:- 
"C. H - aged nine years, sustained a severe injury of the right leg, over which four heavily-laden wagons had passed. The injury extended within the knee-joint; there was considerable prostration. A little brandy having been administered, about forty drops of chloroform were poured on a handkerchicf, and very shortly produced sound sleep, during which, assisted by Dr. Drury and Mr. Piper, I amputated the limb by the flap operation. No pain was felt, until a suture was applied, some little time after the operation. I will now make a few short extracts from my case-book.

"The chloroform did not seem to cause more bleeding than usual; in fact, I should almost say less. Next day, the 10th, ten A.M.: going on well. Seven in the evening: considerable vascular excitement. To take a refrigerant mixture, with black drop.

" c11th.--Norning: free from pain; pulse tranquil; had a good night.

" In spite of various disadvantages, he has progressed most favourably, and to-day, Feb. 21st, the stump was dressed; the wound to a great extent is healed, and looks very healthy.

"In this case the system was saved from the secondary severe shock which would otherwise have followed a painful operation, and which would have still more unduly deranged or expended the nervous influence. I could not have anticipated such a happy progress of a case, accompanied, as it was, by many adverse circumstances. The poor boy lay upon a rude sort of long box; a bed-ridden old man, with ulcers of the leg, was in an opposite corner; close to his uneasy couch was a fire; and the only point in his favour was that of having long felt the privations of poverty. I have never had occasion to employ so much as one drachm of chloroform, generally using about twenty drops, in the first in stance, and gradually adding five or ten drops more, as may be requisite; nor have $I$, in more than two instances, seen it followed by languor. After the previous potation of stimulants, or after a meal, I have occasionally seen sickness supervene.

"There cannot be a doubt that chloroform is a remedy alike potent for evil as for good; but as the same may be said of many of our most valuable remedies, such an objection can have but little weight with the impartial observer. I trust that we shall soon cease to hear of patients writhing with agony under the knife, or have our feelings distressed by the piercing cries of suffering humanity, when an easy and a peaceful repose may take the place of what it ought to be the aim of every medical man to remove and assuage. Dr. Simpson assuredly receives the thanks of every philanthropist, and will have the great satisfaction of knowing he has conferred an inestimable boon on manlxind."

\section{Suggestions for the Employment of Ether and Chloroform in conjunction.}

By Jorn Gabs, Esq., M.R.C.S.E., \&c., Bewdley.

Mr. GABB remarks that " the vapours of ether and of chloroform, when inhaled, though they each give rise to immunity from suffering during operations, \&c., yet appear to operate somewhat differently." He considers that it might "be desirable to add a little of the stimulating effect of the ether to the directly sedative influence of the chloroform. Could not this be done by mixing the two agents in properly ascertained proportions? I should think it likely that about one part ether to two parts chloroform would be the best proportion for the majority of cases; perhaps experience might enable us to vary the relative proportions of the agents according to the constitutional differences of our patients. Looking at the physiological effects of the inhalation of the vapours, I certainly expect great advantages to arise from the combined or mixed influence of the two, over either alone."

On Professional Prejudice against the Use of Anosthetic Agents. Comparison of the effects of Ether and of Chloroform. Value of Ancesthetic Agents in Parturition.

By S. Gower, Esq., M.R.C.S.E. \&c., Hampstead.

WE extract from a lengthened communication on these subjects the following passages:-

"Several communications have lately appeared, advocating, apon theological grounds, the total disuse of ether and chloroform in obstetric cases, and disparaging their value in all cases. What persons are really afraid of, is lest their powerful appliances should, to use the words of the statute, 'do them some grievous bodily injury.' It is only by taking a liberal, rational, temperate, and discriminate view of medicine that we can accustom the public to regard it in its true light.
Medical men have little right to complain of being put down by brute and senseless clamour, if they themselves give the cue to it in their interprofessional discussions. What has led me to make these remarks, is the tone assumed by Dr. Ashwell and other foregoing correspondents. It surely is disingenuous, in speaking of a Casarian operation in which chloroform was employed, terminating unfavourably, to doubt whether or not it was the chloroform that caused the death of a child that was still-born! It is a rare thing for the Casarian operation to turn out well, and it is a common thing for children to be still-born after long-protracted labours. 'Because the penalty upon the sex is severe,' says one, 'don't prevent their feeling the full weight of it.' Why, what is ergot of rye given for, but to abridge its duration; and what essential difference is there between an abridgment of duration and a privation of pain ? He even condescends to the absurdity of reasoning from popular prejudice, as if what people prima facie think about matters of which they necessarily know nothing, we:e worth a pinch of snuff. He might have argued similarly against splints and bandages, in favour of psalms and incantations for the cure of fractured thigh. bones.

"Dr. Simpson, in discovering that there is a something besides sulphuric ether which can numb the sensory system, has, even in this discovery, added largely and meritoriously to the stores of science, and deserves anything rather than envy and hostility in repayment of it; nevertheless, for my own part, I am slow in admitting the preference, which it seems the fashion to give, of chloroform over ether. All discoveries are, in the course of time, fated to reach their own natural level. Chloroform seems to me to be a something half way between ether and prussic acid, and to be, consequently, a weapon requiring more caution than the former, although less perilous than the latter. . . . What was affirmed by me in THE LANCET, three years ago, with respect to tobacco, was the possibility of achieving a conquest of the sensory system by direct means, an assertion which was incredulously received. Now it is found, that although tobacco and other kindred remedies would effect such conquest only in certain cases, upon certain conditions, known or unknown, being present, ether and chloroform will effect it under almost all conditions.

"I beg $t J$ add a few remarks on the recent fatal case of chloroform in the North. There is no doubt that chloroform, whether owing to the peculiar idiosyncrasy, or, more accurately speaking, the feeble vitality of the patient, caused her death. Are we then to venture upon continuing its employment? So far as this case goes, decidedly yes! A man may die of eating a pork chop for supper, but are all mankind thenceforward to look upon animal food of this kind as poison, and refuse to eat it? At the same time it remains an open question, whether a preference is to be given to one anasthetic agent over another, or over others; as also, whether there are cases in which ether, and other cases in which chloroform, is preferable; others, in which the employment of either is inadmissible. Ether is more stimulant; chloroform more directly sedative. Less exhaustion follows, less is likely to follow, the inhalation of ether than of chloroform. Both may be pushed too far. Perhaps ether is more likely to cause congestion of the brain; chloroform, of the lungs. Both are safe in mid wifery cases, owing to the antagonism of alreadyexisting pain; yet less safe than in surgical operations, because the patient may require to be kept during a longer period under their influence. The inhalation of ether does not impede expulsive uterine efforts; this is somewluat disputable as regards chloroform. Under the influence of either, it may be calculated upon, as a rule, that parturition will terminate sooner; the sensory system being numbed, the disturbing forces are weaker and fewer. We get rid of pain, not simply as pain, but as a disturbing force. We have expulsive efforts without pain-a circumstance which we should, judging from experience, have till lately held incredible. Under the influence of ether, these efforts proceed more uninterruptedly.

"Are midwifery patients, then, to be all dosed with chloro. form or with ether in all natural labours, supposing their corisent to be obtained? Upon the whole, I am almost inclined to think not. There are, however, few cases of dystocia in which, at some period, their use is not demanded. Dystocia is usually measured by duration; it should be rather meted out by the capacity of the pelvic aperture, and of the soft parts, the pliancy or rigidity of the latter, and the pain undergone, than solely by the tedionsness of the labour. Again, ether is not to be administered as a substitute for a catheter, when this implement is required, nor must we trust to it with the neglect of an overloaded rectum. The patient having 